\title{
Three copper(II) complexes constructed from a new 1,3,5-triazine derivative ligand
}

\author{
Ya-Pan Wu ${ }^{\text {a }}$, Cui-Juan Wang ${ }^{\text {a }}$, Yao-Yu Wang ${ }^{\text {a,* }}$, Ping Liu ${ }^{a}$, Wei-Ping Wu ${ }^{\text {a }}$, \\ Qi-Zhen Shi ${ }^{\mathrm{a}}$, Shie-Ming Peng ${ }^{\mathrm{b}}$ \\ a Department of Chemistry, Shaanxi Key Laboratory of Physico-inorganic Chemistry, Northwest University, Xi'an 710069, PR China \\ ${ }^{\mathrm{b}}$ Department of Chemistry, National Taiwan University, Taipei, Taiwan
}

Received 2 June 2006; accepted 3 July 2006

Available online 25 July 2006

\begin{abstract}
Three new complexes $\left\{[\mathrm{Cu}(\text { dpdapt })(\mathrm{Hhbd})] \cdot 6 \mathrm{H}_{2} \mathrm{O}\right\}_{n}(\mathbf{1})\left(\right.$ dpdapt $=N, N^{\prime}$-di(2-pyridyl)-2,4-diamino-6-phenyl-1,3,5-triazine, Hhbd $=$ 2-hydroxybutanedioicate dianion), $\left[\mathrm{Cu}(\mathrm{dpdapt})\left(\mathrm{SO}_{4}\right)\right] \cdot 2 \mathrm{H}_{2} \mathrm{O}(2)$ and $[\mathrm{Cu}($ dpdapt $)($ oxa $)] \cdot \mathrm{H}_{2} \mathrm{O}(3)$ (oxa = oxalate dianion) have been synthesized and structurally characterized. The non-covalent interactions of $\pi-\pi$ stacking and hydrogen bonding extend complexes 1-3 into supramolecular architectures, where 1 self-assembles into a 1D polymeric chain by dicarboxylate bridges and exhibits a 3D framework with 1D open channels, while complexes $\mathbf{2}$ and $\mathbf{3}$ display 2D wavelike networks. Interestingly, in $\mathbf{1}$, the host framework encapsulates hexameric water clusters that are connected into 1D arrays by supramolecular association along the 1D open channels. The UV/vis, IR spectra, fluorescence and TG analysis for complexes $\mathbf{1}, \mathbf{2}$ and $\mathbf{3}$ are also discussed.
\end{abstract}

(c) 2006 Elsevier Ltd. All rights reserved.

Keywords: $\mathrm{Cu}(\mathrm{II})$ complexes; Crystal structure; Self-assembly; Polymeric chain; Hexameric water clusters; 1D open channel

\section{Introduction}

In recent years, tremendous effort has been devoted to the rational design of metal coordination complexes with polymeric architectures from transition metals and multifunctional ligands [1-4]. Rapidly great advances have been made and a wide array of polymeric networks, and e.g., chains [5-7], ladders [8], helices [9] and honeycombs [10] have been obtained. Several factors are known to influence the architecture of a polymer [9,11-14], notably the ligand nature (connectivity, topology), the counterions, and the reaction conditions such as solvent, temperature, and pressure. Along this line, in our group we have synthesized a new modified 1,3,5-triazine ligand $N, N^{\prime}$ di(2-pyridyl)-2,4-diamino-6-phenyl-1,3,5-triazine (dpdapt) (see Chart 1) as a building block for supramolecular com-

\footnotetext{
* Corresponding author. Tel.: +8629 88303097; fax: +862988303798. E-mail address: wyaoyu@nwu.edu.cn (Y.-Y. Wang).
}

plexes [15]. Theoretical calculations reveal that the dpdapt ligand possesses two structural features: (1) It functions as a bis-bidentate or a tridentate ligand forming supramolecular complexes. (2) It can possibly display syn-syn-synsyn, syn-syn-anti-anti and anti-anti-anti-anti coordination modes in complexes [15]. As an extension of our previous work, three new complexes, formulated as $\left\{[\mathrm{Cu}(\text { dpdapt })(\mathrm{Hhbd})] \cdot 6 \mathrm{H}_{2} \mathrm{O}\right\}_{n} \quad(\mathbf{1}), \quad\left[\mathrm{Cu}(\right.$ dpdapt $\left.)\left(\mathrm{SO}_{4}\right)\right] \cdot$ $2 \mathrm{H}_{2} \mathrm{O}(2)$ and $\left[\mathrm{Cu}(\right.$ dpdapt)(oxa) $] \cdot \mathrm{H}_{2} \mathrm{O}(3)$, have been successfully synthesized and characterized by single-crystal $\mathrm{X}$-ray diffraction. The dpdapt ligand adopts an all-anti configuration in the crystal structures of the three copper (II) complexes. Complexes $\mathbf{2}$ and $\mathbf{3}$ show 2D wavelike networks, in which $\mathrm{SO}_{4}{ }^{2-}$ and $\mathrm{C}_{2} \mathrm{O}_{4}{ }^{2-}$ display chelate coordination modes, respectively. While complex 1 selfassembles into a 1D polymeric chain by dicarboxylate bridges and exhibits a 3D framework with 1D open channels. Unexpectedly, we found cyclic $\left(\mathrm{H}_{2} \mathrm{O}\right)_{6}$ clusters encapsulated within the host framework of 1 . These clusters are connected into 1D arrays by supramolecular 


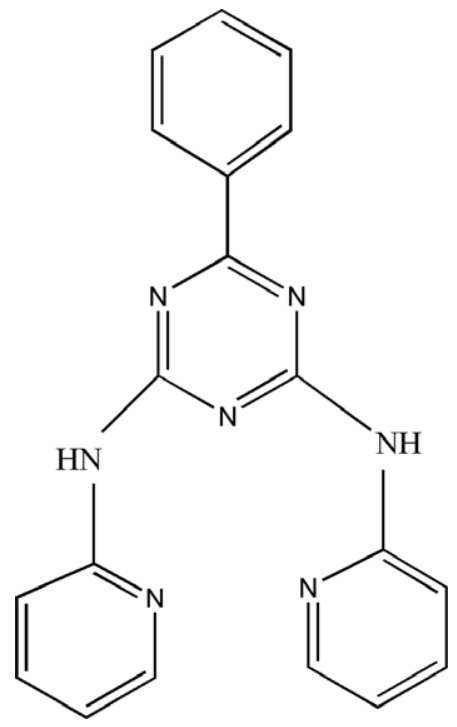

Chart 1. $N, N^{\prime}$-di(2-pyridyl)-2,4-diamino-6-phenyl-1,3,5-triazine(dp dapt).

association running along the $1 \mathrm{D}$ open channels. A recent report described a discrete ice-like hexameric water cluster stabilized by a cyano-bridged trimetallic complex $[16,17]$. Here, the hexameric water cluster is unique and unlike the previously published hexamer water clusters [16-22]. There is mounting evidence of the presence of ordered water clusters in the active clefts of proteins such as dimeric haemoglobin, crambin, actinidin and carbonic anhydrase, however, positional information for the waters and their nature is still preliminary [16,17]. As water molecules play an important role in contributing to conformation, stability, function and dynamics of biomacromolecules, the new 1D water clusters arrays may provide insight into the hydrogen-bonding motif of the aqueous environment in living systems and enhance understanding of the $1 \mathrm{D}$ water morphologies.

\section{Experimental}

\subsection{Materials and physical measurements}

The new ligand $N, N^{\prime}$-di(2-pyridyl)-2,4-diamino-6phenyl-1,3,5-triazine was synthesized according to the literature method [15]. All other reagents and solvents employed were commercially available and used as received without further purification. Infrared spectra on $\mathrm{KBr}$ pellets were recorded on a Nicolet 170SX FT-IR spectrophotometer in the range $4000-400 \mathrm{~cm}^{-1}$. Electronic spectra were taken on a Cary 300 Bio UV-Vis spectrophotometer in the range $200-800 \mathrm{~nm}$ at ambient temperature. Elemental analysis was conducted with a Perkin-Elmer model $240 \mathrm{C}$ instrument. Fluorescence experiments used a HITACHI F-4500 Fluorescence spectrophotometer and were measured in methanol. Thermal analysis was performed on a NETZSCH STA 449C microanalyzer in a nitrogen atmosphere at a heating rate of $10^{\circ} \mathrm{C} \mathrm{min}^{-1}$.

\subsection{Synthesis of $\left\{[\mathrm{Cu}(\text { dpdapt })(\mathrm{Hhbd})] \cdot 6 \mathrm{H}_{2} \mathrm{O}\right\}_{n}(\mathbf{1})$}

A methanol suspension $(15 \mathrm{~mL})$ of dpdapt $(68.2 \mathrm{mg}$, $0.2 \mathrm{mmol}$ ) was added slowly dropwise to methanol $(15 \mathrm{~mL})$ dissolved $\mathrm{Cu}(\mathrm{Hhbd})(42.3 \mathrm{mg}, 0.22 \mathrm{mmol})$. The resulting mixture was stirred for $30 \mathrm{~min}$ and then filtered. The aqua filtrate solution was transferred a tube and evaporated at room temperature. After two months, deep blue crystals were obtained. Yield: 65\%. Anal. Calc. for $\mathrm{C}_{23} \mathrm{H}_{31} \mathrm{CuN}_{7} \mathrm{O}_{11}$ (645.09): C, 41.78; H, 4.74; N, 14.83 . Found: C, 41.91; H, 4.70; N, 14.72\%. IR spectrum $\left(\mathrm{cm}^{-1}\right):$ 3425(w), 2923(w), 1640(s), 1592(m), 1502(w), 1469(s), 1429(s), 1381(s), 1242(w), 1195(w), 1157(w), 1023(w), 891(w), 821(w), 773(m), 703(w), 633(w), 525(w).

\subsection{Synthesis of $\left[\mathrm{Cu}(\right.$ dpdapt $\left.)\left(\mathrm{SO}_{4}\right)\right] \cdot 2 \mathrm{H}_{2} \mathrm{O}(2)$}

$\mathrm{CuSO}_{4} \cdot 5 \mathrm{H}_{2} \mathrm{O}(50.0 \mathrm{mg}, 0.2 \mathrm{mmol})$ was dissolved in methanol $(15 \mathrm{~mL})$ and mixed with a methanol suspension $(15 \mathrm{~mL})$ of dpdapt $(68.2 \mathrm{mg}, 0.2 \mathrm{mmol})$ and then stirred for $1 \mathrm{~h}$. Diffused in $\mathrm{Et}_{2} \mathrm{O}$ after filtration, finally blue crystals were produced. Yield: 59\%. Anal. Calc. for $\mathrm{C}_{19} \mathrm{H}_{19} \mathrm{Cu}-$ $\mathrm{N}_{7} \mathrm{O}_{6} \mathrm{~S}$ (537.01): C, 42.50; H, 3.57; N, 18.26. Found: C, 42.32; H, 3.43; N, 18.38\%. IR spectrum $\left(\mathrm{cm}^{-1}\right)$ : 3493(w), 2925(w), 1636(s), 1587(s), 1502(m), 1469(s), 1434(s), 1242(w), 1195(w), 1162(w), 977(w), 867(w), 832(w), 770(m), 696(w), 634(w), 517(w), 432(w).

\subsection{Synthesis of $[\mathrm{Cu}($ dpdapt $)($ oxa $)] \cdot \mathrm{H}_{2} \mathrm{O}(3)$}

$\mathrm{Cu}$ (oxa) (30.3 mg, $0.2 \mathrm{mmol}$ ) was dissolved in methanol $(15 \mathrm{~mL})$ and mixed with a methanol suspension $(15 \mathrm{~mL})$ of dpdapt (68.2 $\mathrm{mg}, 0.2 \mathrm{mmol})$ and then stirred for $2 \mathrm{~h}$. Green crystals 3 were obtained after the mixture was allowed to stand at room temperature for a month. Yield: $60 \%$. Anal. Calc. for $\mathrm{C}_{21} \mathrm{H}_{17} \mathrm{CuN}_{7} \mathrm{O}_{5}$ (510.96): C, 51.16; H, 3.07; N, 19.89. Found: C, 51.33; H, 2.94; N, 19.73\%. IR spectrum $\left(\mathrm{cm}^{-1}\right)$ : 3411(w), 2913(w), 1665(s), 1573(m), 1510(w), 1466(s), 1385(s), 1269(w), 1240(w), 1202(w), 1157(w), 1115(w), 1059(w), 1023(w), 779(m), 706(w), 627(w), 524(w).

\subsection{Crystallographic data collection and structure determination}

Single-crystal X-ray diffraction of complexes 1, 2 and $\mathbf{3}$ were performed on a BRUKER SMART 1000 CCD diffractometer equipped with a graphite crystal monochromator situated in the incident beam for data collection. Crystallographic data were collected with Mo K $\alpha$ radiation ( $\lambda=0.71073 \AA$ ) for the three complexes at 296(2) K. The structures were solved by direct methods and refined by full-matrix least-squares method on $F^{2}$ values using SHELXL 97 and SHELXL 97 programs, respectively [23,24]. Single crystal X-ray structural analysis shows the hydroxyl group might lie on one of the two adjacent methylenes, which would present the hydroxyl group disordered in a halfoccupied position in complex 1. All non-hydrogen atoms 
were refined with anisotropic displacement parameters. Hydrogen atoms of all water molecules in complex 1 were not visible in the difference Fourier map. In complexes 2 and $\mathbf{3}$, the hydrogen atoms of the lattice water molecules could be trustfully inferred from analysis of the difference Fourier map. Crystal data, data collection and refinement parameters for three complexes are shown in Table 1, and selected bond lengths and bond angles are listed in Table 2.

\section{Results and discussion}

\subsection{Description of the crystal structures}

A single crystal X-ray structural analysis shows $\mathbf{1}$ crystallizes in monoclinic space group $C_{2} / \mathrm{c}$. Each copper atom has a slightly distorted $\left[\mathrm{CuN}_{3} \mathrm{O}_{2}\right]$ trigonal bipyramid geometry. Owing to the symmetry of the ligand, each copper atom lies on a two-fold axis in the subunit (Fig. 1). The

Table 1

Crystallographic data and structure refinement for $\mathbf{1 , 2}$ and $\mathbf{3}$

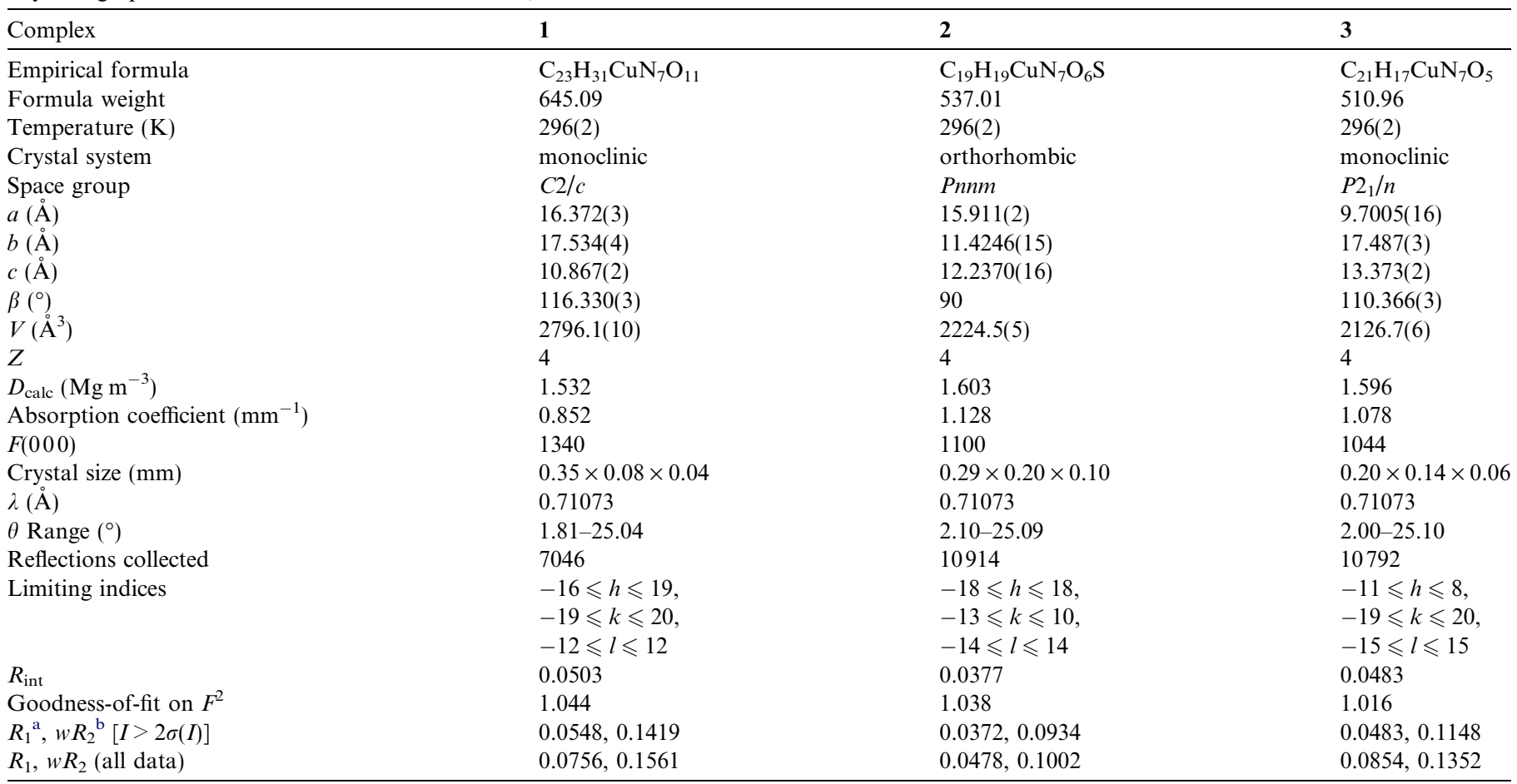

${ }^{\mathrm{a}} R=\sum \| F_{\mathrm{o}}|-| F_{\mathrm{c}}\left|/ \sum\right| F_{\mathrm{o}} \mid$.

${ }^{\mathrm{b}} w R_{2}=\left[\sum\left[w\left(F_{\mathrm{o}}^{2}-F_{\mathrm{c}}^{2}\right)^{2}\right] / \sum\left[\left(F_{\mathrm{o}}^{2}\right)^{2}\right]\right]^{1 / 2}$.

Table 2

Selected bond lengths $(\AA)$ and angles $\left({ }^{\circ}\right)$ of complexes $\mathbf{1}, 2$ and 3

\begin{tabular}{|c|c|c|c|c|c|}
\hline \multirow{2}{*}{1} & & \multicolumn{2}{|l|}{2} & \multicolumn{2}{|l|}{3} \\
\hline & & & & & \\
\hline Cu1-N1\#1 & $1.978(3)$ & $\mathrm{Cu} 1-\mathrm{N} 1$ & $1.979(2)$ & $\mathrm{Cu} 1-\mathrm{N} 1$ & 2.013(3) \\
\hline $\mathrm{Cu} 1-\mathrm{N} 1$ & $1.978(3)$ & $\mathrm{Cu} 1-\mathrm{N} 1 \# 2$ & $1.979(2)$ & $\mathrm{Cu} 1-\mathrm{N} 3$ & $1.954(3)$ \\
\hline Cu1-O1\#1 & $2.096(3)$ & $\mathrm{Cu} 1-\mathrm{O} 2$ & $2.208(3)$ & Cu1-O1 & $1.912(3)$ \\
\hline $\mathrm{Cu} 1-\mathrm{O} 1$ & $2.096(3)$ & $\mathrm{Cu} 1-\mathrm{O} 3$ & $1.961(2)$ & $\mathrm{Cu} 1-\mathrm{O} 2$ & $2.064(3)$ \\
\hline N3-Cu1-O1\#1 & $134.3(9)$ & $\mathrm{O} 2-\mathrm{Cu} 1-\mathrm{N} 1 \# 2$ & $114.5(8)$ & $\mathrm{N} 1-\mathrm{Cu} 1-\mathrm{O} 2$ & $133.4(1)$ \\
\hline $\mathrm{O} 1-\mathrm{Cu} 1-\mathrm{O} 1 \# 1$ & $91.6(2)$ & $\mathrm{N} 1-\mathrm{Cu} 1-\mathrm{O} 2$ & $114.5(8)$ & $\mathrm{N} 7-\mathrm{Cu} 1-\mathrm{O} 2$ & $103.9(2)$ \\
\hline N1-Cu1-N1\#1 & $174.2(2)$ & $\mathrm{N} 4-\mathrm{Cu} 1-\mathrm{O} 3$ & $163.2(9)$ & N3-Cu1-O1 & $170.9(1)$ \\
\hline \multicolumn{6}{|l|}{ Hydrogen bonds } \\
\hline $\mathrm{N} 2-\mathrm{H} \cdots \mathrm{O} 2^{\mathrm{a}}$ & $2.832(4)$ & $\mathrm{N} 2-\mathrm{H} \cdots \mathrm{O} 4^{\mathrm{b}}$ & $2.794(5)$ & $\mathrm{O} 9-\mathrm{H} \cdots \mathrm{O} 3^{\mathrm{d}}$ & $2.687(5)$ \\
\hline $\mathrm{O} 3-\mathrm{H} \cdots \mathrm{O} 4$ & $2.729(2)$ & $\mathrm{O} 4-\mathrm{H} \cdots \mathrm{O} 1^{\mathrm{c}}$ & $2.738(4)$ & $\mathrm{O} 9-\mathrm{H} \cdots \mathrm{O} 4^{\mathrm{e}}$ & $2.855(5)$ \\
\hline
\end{tabular}

Symmetry codes: \#1: $-x+1, y,-z+1 / 2$; \#2: $x, y,-z+1$; (a) $-x+1,-y+2,-z+1$; (b) $x, y,-z+1$; (c) $x+1 / 2,-y+1 / 2, z+1 / 2$; (d) $x, y, z-1$; (e) $x+1 / 2,-y+1 / 2, z-1 / 2$; (f) $x-1, y, z+1$. 


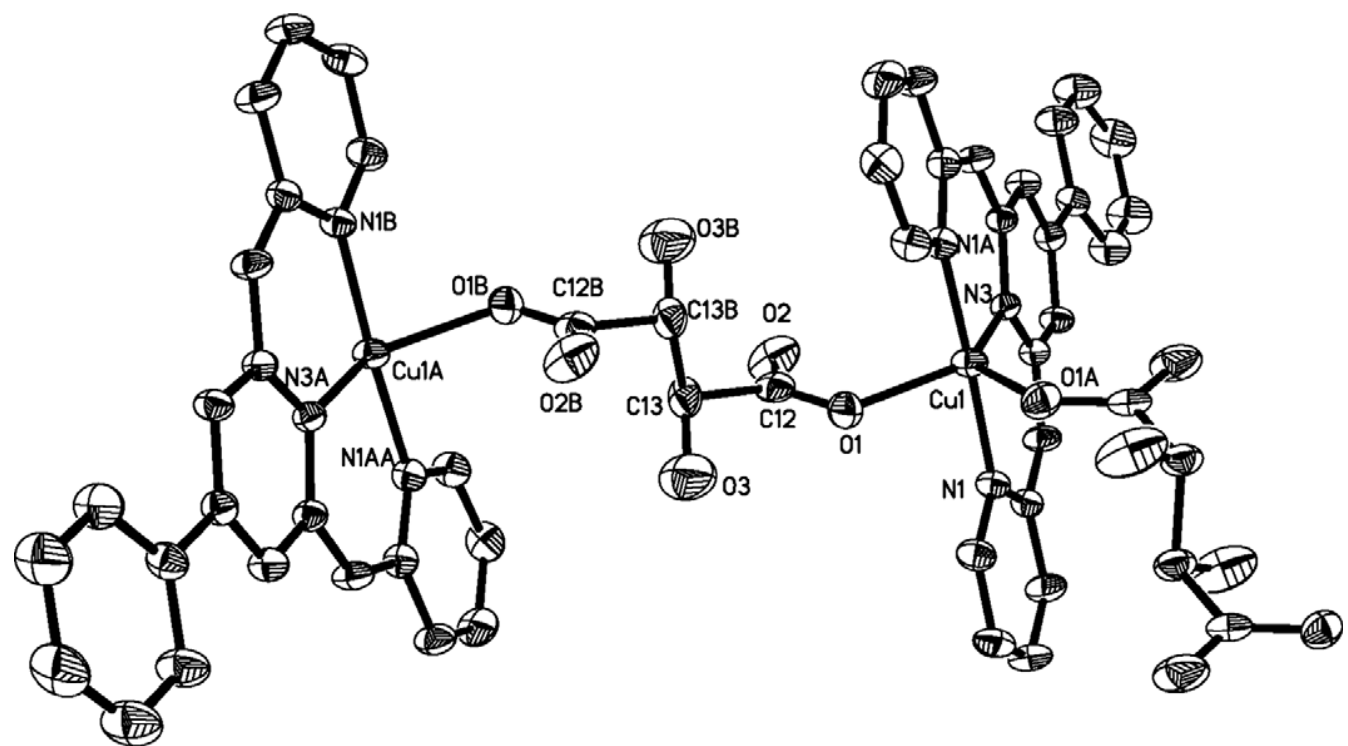

Fig. 1. Repeat unit of the infinite coordination polymer of $\mathbf{1}$. Thermal ellipsoids are drawn at the $30 \%$ probability level. Hydrogen atoms and water molecules are omitted for clarity.

copper (II) ion is coordinated to three nitrogen atoms from the dpdapt ligand, and two oxygen atoms from two different Hhbd dianions. The two pyridyl rings of the dpdapt ligand are nearly coplanar with a dihedral angle of ca. $4.5^{\circ}$. It is worthwhile to note that the Hhbd dianions bridge copper centers to create a $1 \mathrm{D}$ polymeric chain running along the $a$ axis with an adjacent $\mathrm{Cu} \cdots \mathrm{Cu}$ distance of $8.957(2) \AA$. The dpdapt ligands lie on both sides of this 1D chain in an antiparallel fashion. Interestingly, these 1D polymeric chains self-assemble to generate a $2 \mathrm{D}$

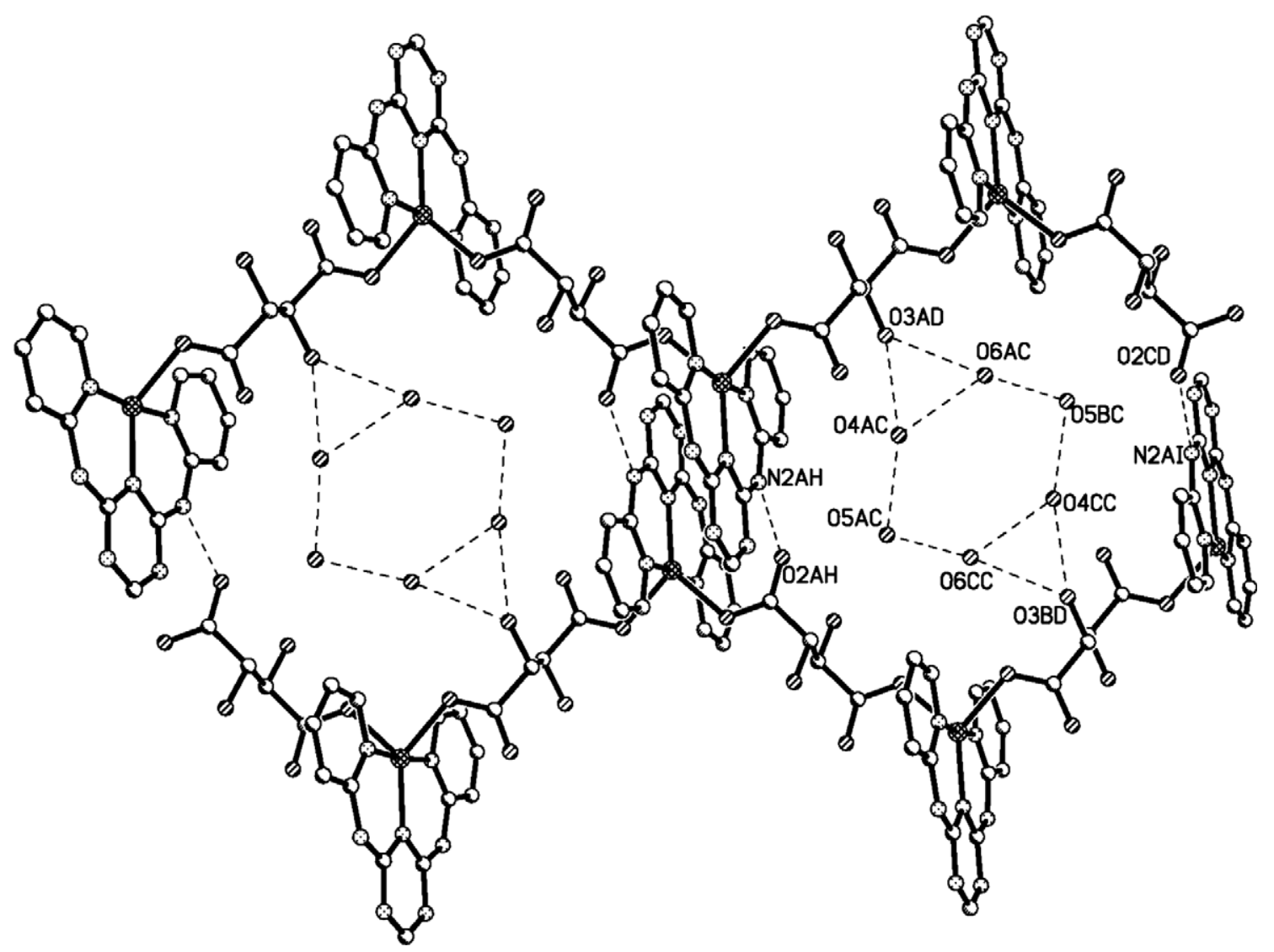

Fig. 2. View of the 2D supramolecular structure of complex 1 self-assembled by hydrogen bonds and $\pi-\pi$ stacking interactions. 
supramolecular architecture under the direction of hydrogen bonding $\left(\mathrm{N}_{\text {amido }}-\mathrm{H} \cdots \mathrm{O}_{\text {carbonyl }}, 2.832(4) \AA\right)$ and $\pi-\pi$ stacking interactions between the pyridyl and triazine ring with a center-to-center distance of $3.55 \AA$ and with a dihedral angle of ca. $2.7^{\circ}$ (Symmetry code: $-x,-y,-z$ ) (Fig. 2). There are also significant hydrogen bonds involving hydroxyl oxygen atoms (O3AD, O3BD) of the dicarboxylate ligands and aqua oxygen atoms $(\mathrm{O} 4 \mathrm{AC}, \mathrm{O} 6 \mathrm{AC}, \mathrm{O} 4 \mathrm{CC}$, O5AC, O5BC, O6CC) from lattice water molecules. These observed hydrogen bonding interactions, with the donoracceptor distances, are shown in Tables 2 and 3. These interactions generate the final 3D framework that feature 1D open channels $(14.626 \times 15.110 \AA)$ when viewed along the $c$ axis (Fig. 3).

The most remarkable feature in $\mathbf{1}$ is that these $1 \mathrm{D}$ channels are occupied by six water molecules, which are

Table 3

Geometrical parameters $\left[\AA{ }^{\circ}\right]$ for the cyclic water hexamers in complex $\mathbf{1}$

\begin{tabular}{llll}
\hline $\mathrm{O}-\mathrm{H} \cdots \mathrm{O}$ & $\mathrm{O} \cdots \mathrm{O}$ & $\mathrm{O} \cdots \mathrm{O} \cdots \mathrm{O}$ & \\
\hline $\mathrm{O} 4-\mathrm{H} \cdots \mathrm{O}^{\mathrm{a}}$ & $2.783(9)$ & $\mathrm{O} 4 \cdots \mathrm{O} 5 \cdots \mathrm{O} 6$ & $107.44(2)$ \\
$\mathrm{O} 4-\mathrm{H} \cdots \mathrm{O} 6$ & $2.844(5)$ & $\mathrm{O} 5 \cdots \mathrm{O} 6 \cdots \mathrm{O} 4$ & $128.73(2)$ \\
$\mathrm{O} 5-\mathrm{H} \cdots \mathrm{O} 6$ & $2.887(5)$ & $\mathrm{O} 6 \cdots \mathrm{O} 4 \cdots \mathrm{O} 5$ & $123.72(2)$ \\
$\mathrm{O} 6-\mathrm{H} \cdots \mathrm{O} 6$ & $2.633(1)$ & & \\
\hline
\end{tabular}

Symmetry codes: (a) $-x+3 / 2, y-1 / 2,-z+3 / 2$. associated by strong $\mathrm{O}-\mathrm{H} \cdots \mathrm{O}$ hydrogen bonds into cyclic centrosymmetric hexamers that adopt a hexagon configuration (Fig. 4(a)). The geometric parameters of the hexamers are summarized in Table 3 . The average distance between the oxygen atoms is $2.838(6) \AA$, which is very similar to the $\mathrm{O} \cdots \mathrm{O}$ distance of $2.85 \AA$ in liquid water [25]. Unlike the previously reported hexamer clusters [16-22], here it is noteworthy that the water hexamer clusters are self-assembled along the channels by interhexamer 06...06 hydrogen bonds to give extended 1D arrays consisting of six-membered rings of water (Fig. 4(a)). When viewed down the crystallographic $c$ axis, more interestingly, an adjacent hexameric water cluster is not complete superposition but is in a slipped stacking mode (Fig. 4(b)).

Additionally, the hydrogen bonding between water molecules and the hydroxyl oxygen atoms of dicarboxylate ligands plays an important role in contributing to the stability of the $1 \mathrm{D}$ hexameric water cluster arrays. This supramolecular association of water molecules in arrays is presumably enforced by the shape and the condition of the interior of the host's channel. These results further illustrate the structural diversity possible for water clusters and the sensitive dependence of their structures on the nature of their environment.

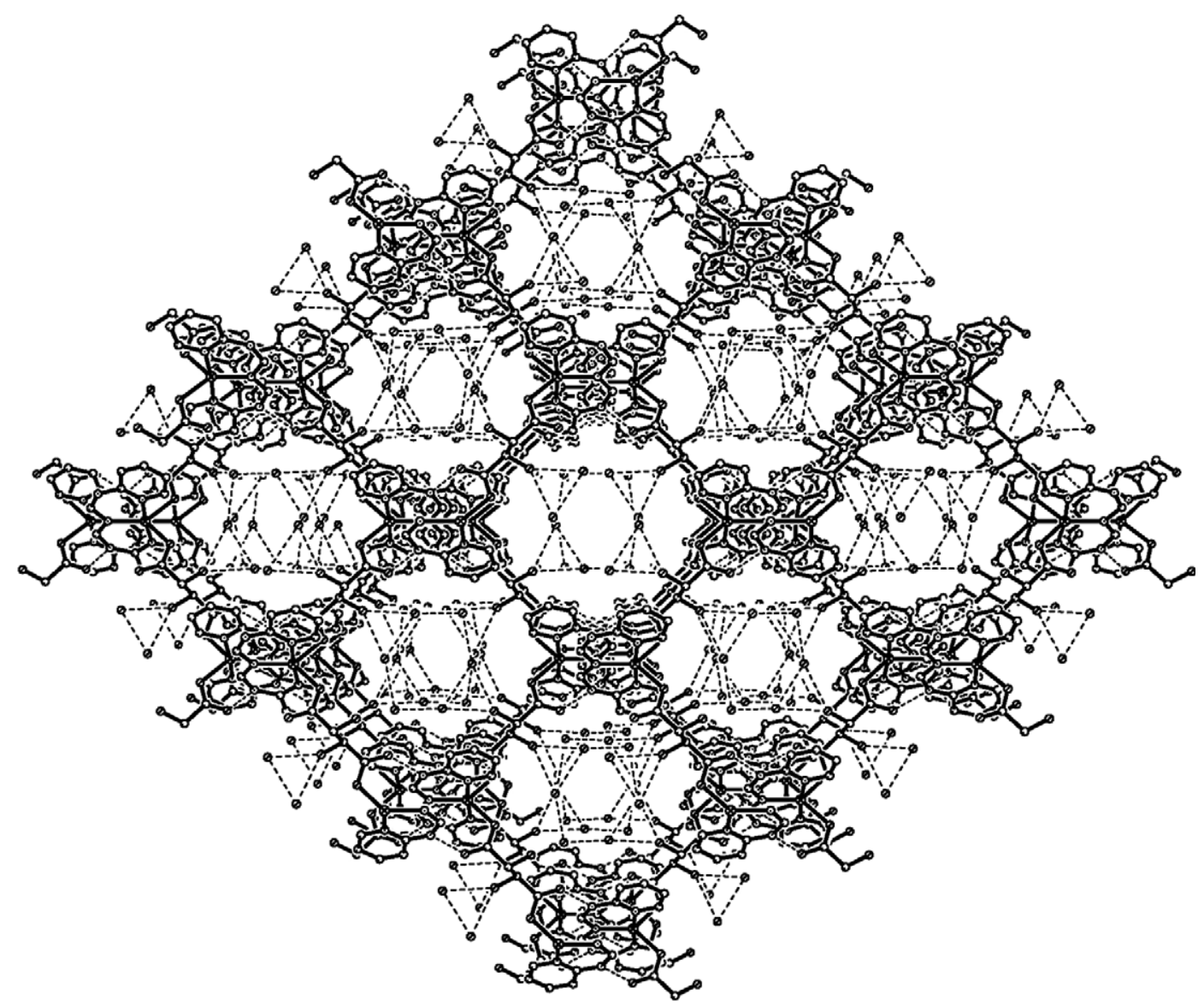

Fig. 3. View of the 3D supramolecular framework of complex 1 that contains $1 \mathrm{D}$ open channels encapsulating arrays of cyclic $\left(\mathrm{H}_{2} \mathrm{O}\right)_{6}$ clusters. 


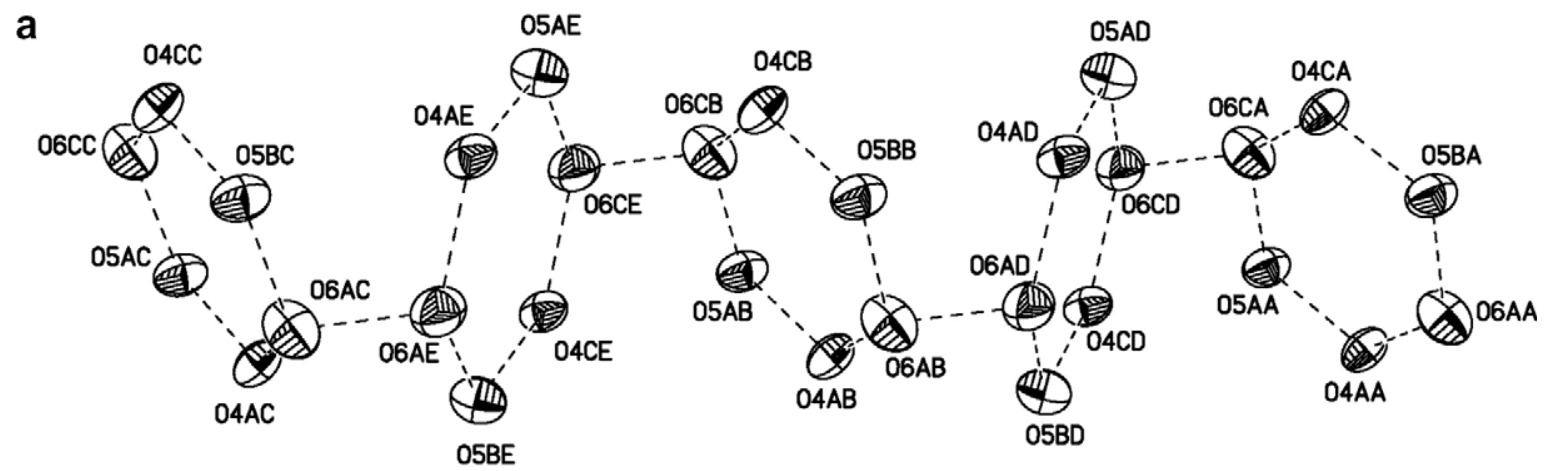

b

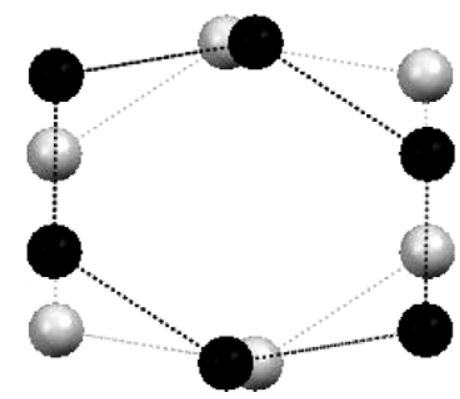

Fig. 4. (a) Extended 1D array consisting of six-membered rings of water molecules in the 3D framework of complex 1 . The hydrogen bond $\mathrm{O} \cdots \mathrm{O}$ distances $[\AA]$ : O5AB $\cdots \mathrm{O} 4 \mathrm{AB}, 2.783(9)$; O4AB $\cdots \mathrm{O} 6 \mathrm{AB}, 2.844(5)$; O6AB $\cdots \mathrm{O} 5 \mathrm{BB}, 2.887(5)$. (b) View of hexameric water cluster array in the 1D open channels of complex 1. Black and grey represent the different array of an adjacent cyclic $\left(\mathrm{H}_{2} \mathrm{O}\right)_{6}$ cluster. Dotted lines show the hydrogen bonding between water molecules.

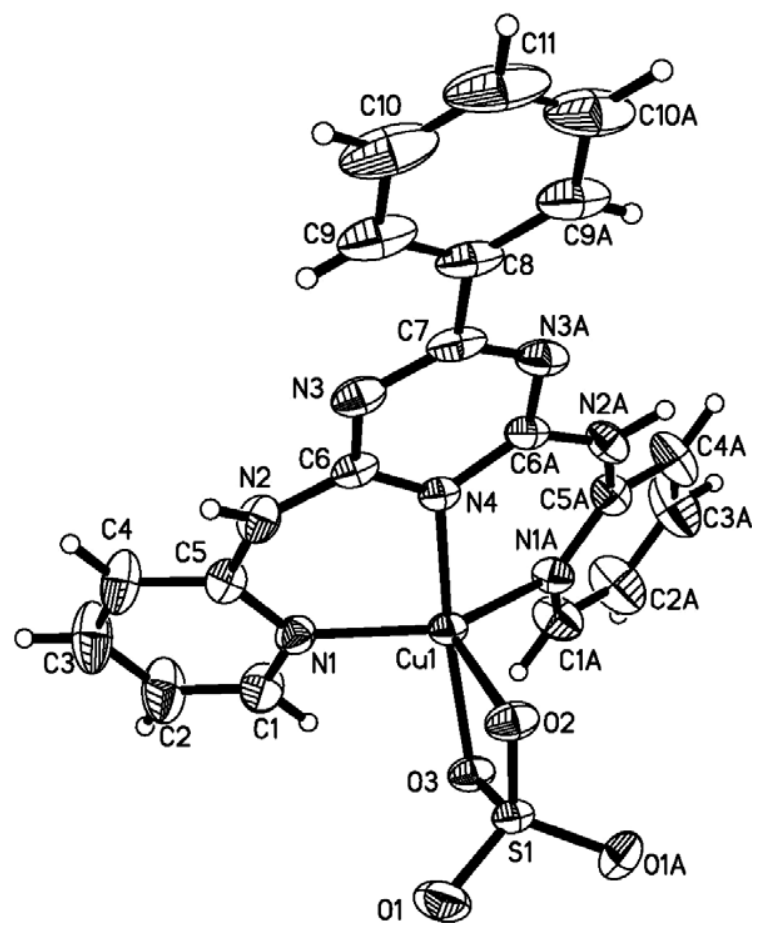

Fig. 5. ORTEP view of $\left[\mathrm{Cu}(\right.$ dpdapt $\left.)\left(\mathrm{SO}_{4}\right)\right] \cdot 2 \mathrm{H}_{2} \mathrm{O}(2)$ with $30 \%$ probability ellipsoids. The water molecules are omitted here.

The molecular structure of $\mathbf{2}$ is shown in Fig. 5. The complex crystallizes in the orthorhombic space group Pnnm. The Cu1 is five-coordinate being bonded in a bidentate fashion to two oxygen atoms $(\mathrm{O} 2, \mathrm{O} 3)$ of the sulfate dianion and in a tridentate fashion to one triazine- $\mathrm{N}$ atom (N4) and two pyridine-N atoms (N1, N1A). The two pyridyl rings of the dpdapt ligand are non-coplanar with a dihedral angle of ca. $52.2^{\circ}$. In mononuclear [Cu(dpdapt) $\left.\left(\mathrm{SO}_{4}\right)\right] \cdot 2 \mathrm{H}_{2} \mathrm{O}$, the bond angles $\mathrm{N} 1-\mathrm{Cu} 1-\mathrm{N} 1 \mathrm{~A}\left(130.4(5)^{\circ}\right)$, $\mathrm{N} 1 \mathrm{~A}-\mathrm{Cu} 1-\mathrm{O} 2\left(114.5(8)^{\circ}\right)$ and $\mathrm{O} 2-\mathrm{Cu} 1-\mathrm{N} 1\left(114.5(8)^{\circ}\right)$ add up to approximately to $360^{\circ}$ and the angle N4-Cu1$\mathrm{O} 3$ is close to $180^{\circ}$, so the coordinated geometry of the central copper can be described as a distorted trigonal bipyramid configuration, $\mathrm{Cu} 1, \mathrm{~N} 1, \mathrm{~N} 1 \mathrm{~A}, \mathrm{O} 2$ forming the equatorial plane and $\mathrm{N} 4, \mathrm{O} 3$ occupying the axial positions. The lattice water molecules act as a hydrogen bond donor/ acceptor, forming hydrogen bonds with the oxygen atoms of the sulfate anion and the amido nitrogen atoms (as shown in Table 2), to give rise to a $2 \mathrm{D}$ network structure in the $a c$ plane as shown in Fig. 6.

Complexes $\mathbf{3}$ and $\mathbf{1}$ have the same crystal system and different space group, and complex 3 displays a $P 2_{1} / n$ space group. The central copper(II) is five-coordinate being bonded in a bidentate fashion to two oxygen atoms $(\mathrm{O} 1, \mathrm{O} 2)$ of an oxalate dianion and in a tridentate fashion to one triazine- $\mathrm{N}$ atom (N3) and two pyridine- $\mathrm{N}$ atoms (N1, N7) (Fig. 7). The dihedral angle between the two pyridyl ring planes of the dpdapt ligand is $38.9^{\circ}$. The bonds distance to the terminal triazine $\mathrm{N} 3(\mathrm{Cu} 1-\mathrm{N} 3)$ is 1.954(3) $\AA$ and the distance with the pyridyl donors N1 and N7 are 2.013(3) and 2.068(3) $\AA$, respectively. The average $\mathrm{Cu}-\mathrm{N}$ bond length is observed to be 2.011(9) $\AA$, which is longer than that of $\mathbf{1}$. Both $\mathrm{Cu}-\mathrm{N}$ bond lengths are typical of those found for five-coordinate $\mathrm{Cu}(\mathrm{II})-\mu$ - 


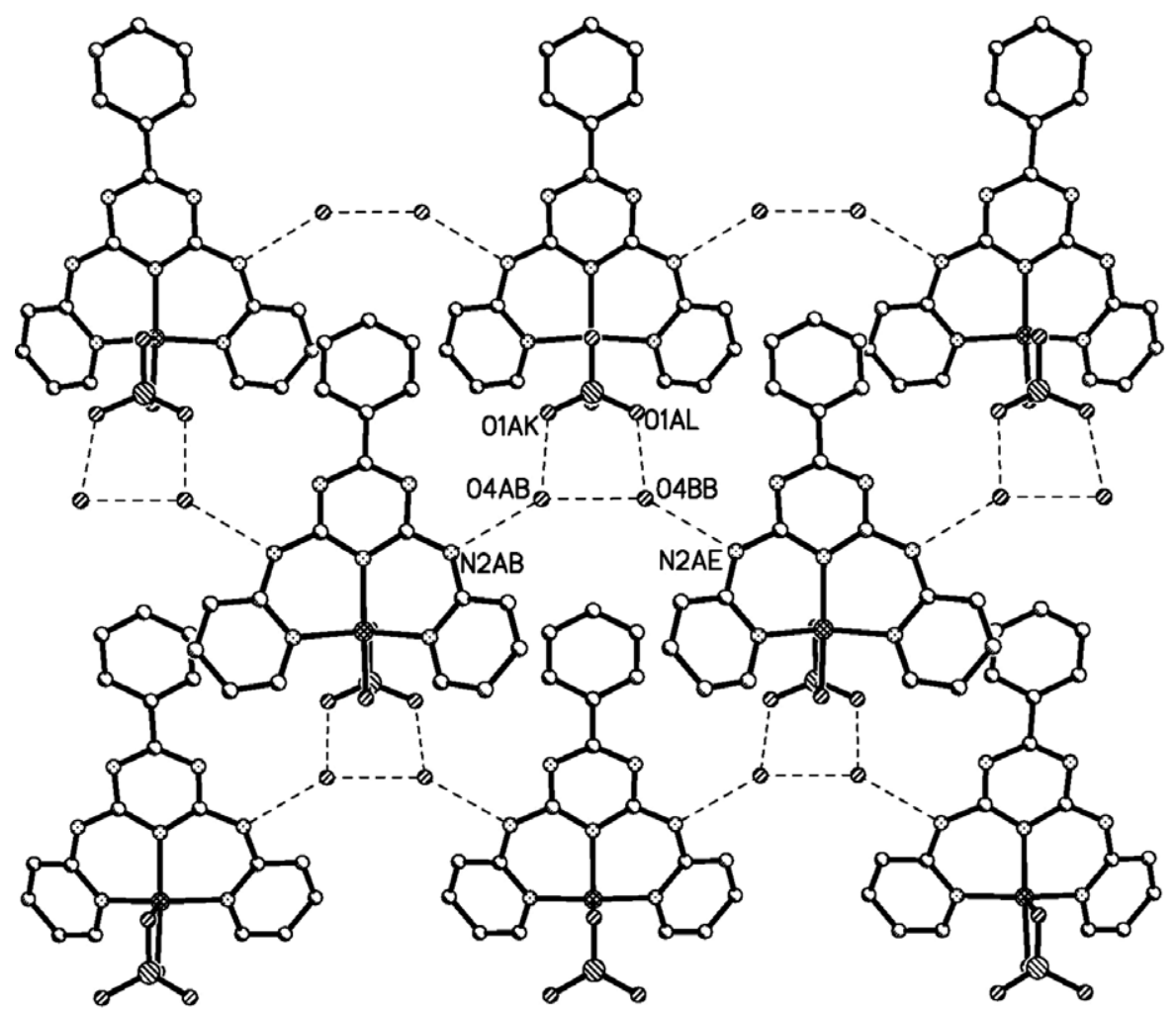

Fig. 6. View of the $2 \mathrm{D}$ network of $\left[\mathrm{Cu}(\right.$ dpdapt $\left.)\left(\mathrm{SO}_{4}\right)\right] \cdot 2 \mathrm{H}_{2} \mathrm{O}(2)$ constructed through two kinds of hydrogen bonds $(\mathrm{O}-\mathrm{H} \cdots \mathrm{O}, \mathrm{N}-\mathrm{H} \cdots \mathrm{O})$ in the $a c$ plane.

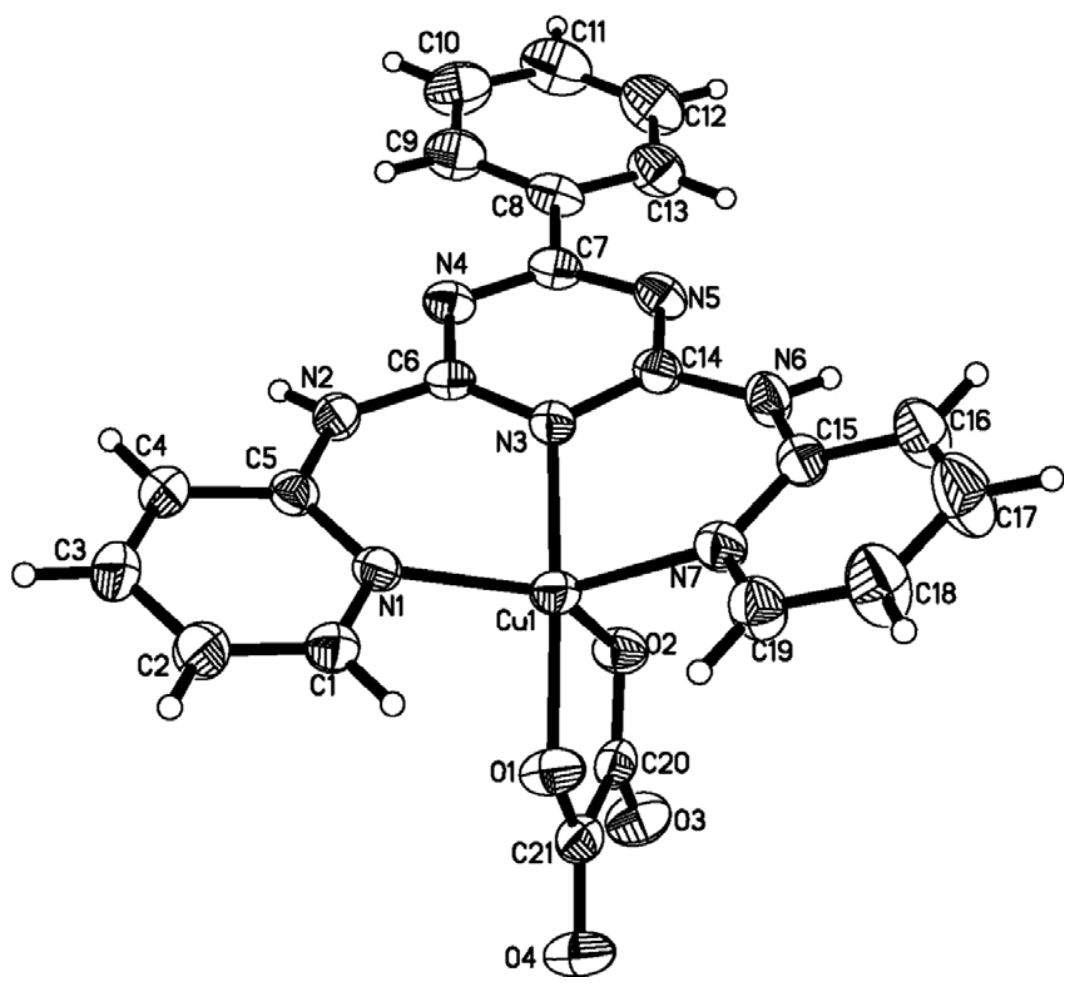

Fig. 7. Perspective view of the coordination environment of the copper atom in the complex $[\mathrm{Cu}(\mathrm{dpdapt})(\mathrm{oxa})] \cdot \mathrm{H}_{2} \mathrm{O}(\mathbf{3})$. Thermal ellipsoids are drawn at the $30 \%$ probability level. One water molecule is omitted here.

pmea analogues [26]. The adjacent monomeric entity is interconnected through hydrogen bonding interactions involving the oxygen atoms of the lattice water molecule and the oxalate dianion and the amido nitrogen atoms (Table 2), to generate a $2 \mathrm{D}$ wavelike network in the $a c$ plane (Fig. 8). 


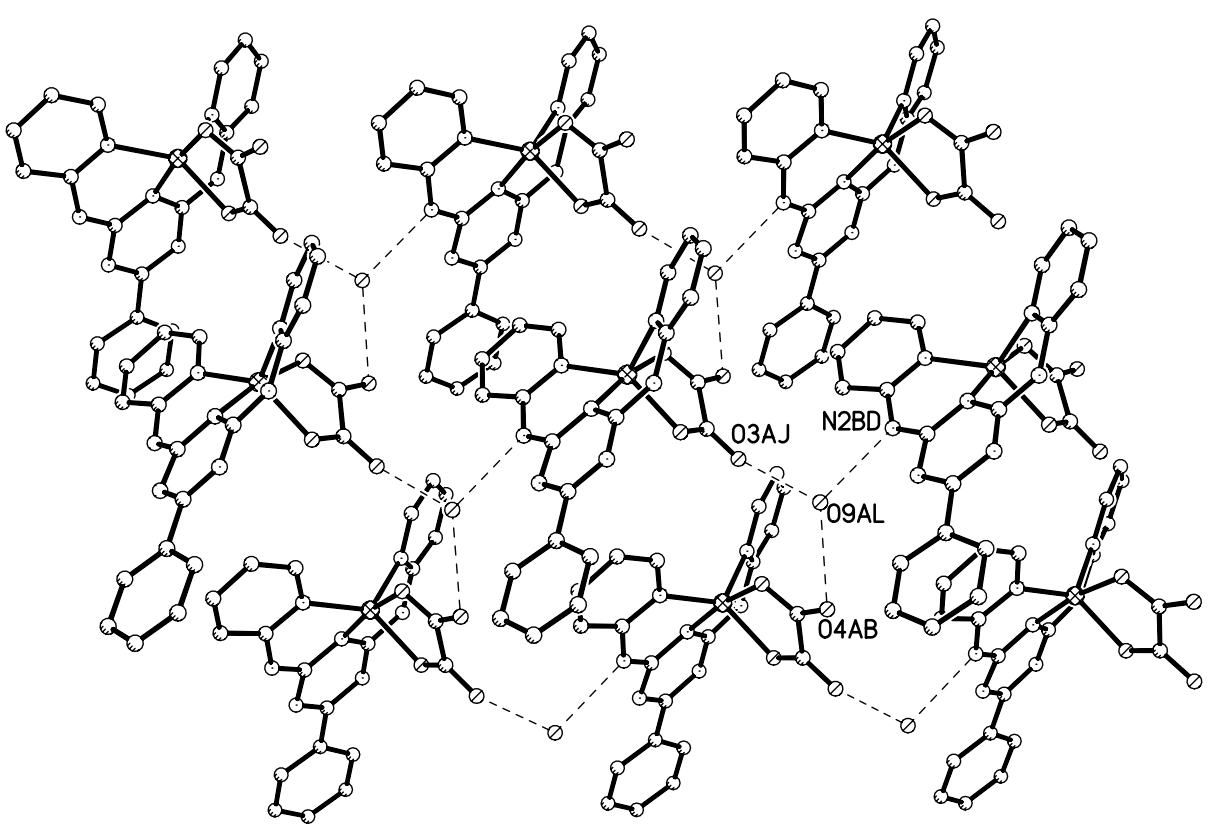

Fig. 8. View of the 2D supramolecular network of $[\mathrm{Cu}(\mathrm{dpdapt})(\mathrm{oxa})] \cdot \mathrm{H}_{2} \mathrm{O}$ (3) formed by hydrogen bonds $(\mathrm{O} 9 \mathrm{AL}-\mathrm{H} \cdots \mathrm{O} 3 \mathrm{AJ}, 2.687(5) \AA$, O9AL$\mathrm{H} \cdots \mathrm{O} 4 \mathrm{AB}, 2.855(5) \AA$; N2BD-H $\cdots \mathrm{O} 9 \mathrm{AL}, 2.730(5) \AA$ ). The hydrogen atoms of the lattice water molecules and the organic ligand are omitted for clarity here.

Although the structures of $\mathbf{1}, \mathbf{2}$ and $\mathbf{3}$ exhibit the coordination character of the dpdapt ligand in part, the framework structures of the three complexes are rare for inorganic triazine compounds. To the best of our knowledge only one dimeric unit of a transition-metal complex based on 1,3,5-tris(2-pyridyl)triazine (tpt) has been reported [27], but no solvent molecules effect and $\pi-\pi$ interactions were discussed. Additionally, in our previous works, two complexes have been reported [15], which show ladder and layer frameworks via intermolecular and intramolecular hydrogen bonds, respectively. However, we discuss here the action of guest solvent molecules in constructing the three complexes. There are hexameric, dimeric and one water molecule located in the lattices of complexes $\mathbf{1}, \mathbf{2}$ and $\mathbf{3}$, respectively. It is the water molecules that extend complexes $\mathbf{2}$ and $\mathbf{3}$ into $2 \mathrm{D}$ supramolecular networks. While in $\mathbf{1}$, water molecules form a hexagon configuration in the adjacent 1D polymeric chains, Furthermore, the individual water hexamer self-assembles $1 \mathrm{D}$ chains by interhexamer hydrogen bonds, which exert a great influence on extending the architecture of complex 1.

\subsection{Spectroscopic properties}

The IR spectra of the three complexes were performed as $\mathrm{KBr}$ pellets in the range $4000-400 \mathrm{~cm}^{-1}$. In complex 1 , the bands around 1425 and $1496 \mathrm{~cm}^{-1}$ for the ligand dpdapt, attributed to the $\mathrm{C}=\mathrm{N}$ groups, are shifted to 1469 and $1592 \mathrm{~cm}^{-1}$. In complex 2 , the corresponding bands for the $\mathrm{C}=\mathrm{N}$ groups are shifted to 1469 and $1587 \mathrm{~cm}^{-1}$, the bands corresponding to $\mathrm{SO}_{4}{ }^{2-}$ are at $634 \mathrm{~cm}^{-1}$. The corresponding bands for the $\mathrm{C}=\mathrm{N}$ groups for 3 are shifted to 1466 and $1573 \mathrm{~cm}^{-1}$, respectively. Furthermore, the spectra exhibit $v_{\mathrm{as}}(\mathrm{OCO})$ and $v_{\mathrm{s}}(\mathrm{OCO})$ vibrations of the carboxylate groups that occur at 1640 and $1381 \mathrm{~cm}^{-1}$ for $\mathbf{1}$ and 1665 and $1385 \mathrm{~cm}^{-1}$ for 3. $\Delta\left[v_{\mathrm{as}}(\mathrm{OCO})-v_{\mathrm{s}}(\mathrm{OCO})\right]>$ $200 \mathrm{~cm}^{-1}$ for complexes $\mathbf{1}$ and $\mathbf{3}$, and the value reveals that the carboxylate is coordinated in a monodentate fashion, which is consistent with the results of the X-ray analysis. These data confirm the involvement of acid radical ligands and ligand dpdapt in the copper complexation. The UVVis spectra of the complexes are recorded in methanol and are characterized by several spectral regions. The absorption bands in the range $260-285 \mathrm{~nm}$ for the dpdapt ligand are ligand-centered (LC) due to $\pi-\pi^{*}$ transitions. The peak at $300 \mathrm{~nm}$ for complexes $\mathbf{1}, \mathbf{2}$ and $\mathbf{3}$ is due to the $\mathrm{d}-\mathrm{d}$ transition and the low-energy bands at 300,302 and $297 \mathrm{~nm}$ are assigned to metal-to-ligand charge transfer transitions (MLCT) [28,29]. This slight shift of absorption bands of the complexes relative to that of dpdapt is caused by the effect of metal-to-ligand charge transfer transitions.

The luminescence data were obtained in methanol at room temperature. It was reported that the dpdapt ligand showed a strongest emission peak at $375.4 \mathrm{~nm}$ with an excitation peak at $330.0 \mathrm{~nm}$ [15]. The emission bands for complexes 1, 2 and 3 can be attributed to intraligand fluorescent emission of the coordinated dpdapt ligand. The emission peak for complex $\mathbf{1}$ is at $310.8 \mathrm{~nm}$, for complex 2 at $330.6 \mathrm{~nm}$ and for complex 3 at $320.2 \mathrm{~nm}$, and their emission spectra show strong peaks at 448.6, 414.2 and $423.6 \mathrm{~nm}$, respectively. Compared with the excitationemission spectrum of the ligand, obvious enhancement of the fluoroscence intensities is realized in complexes $\mathbf{1}, \mathbf{2}$ and 3; the emission bands for three complexes are redshifted. This drastic shift can be attributed to the strong hydrogen-bonding interactions between the water 
molecules and the nearby $\mathrm{O}$ atoms of acid radical ligands that change the donor-acceptor character of the dpdapt moieties. These peaks of the emission spectra are probably assigned to intramolecular charge transfer (ICT) transitions [30].

\subsection{Thermogravimetric analysis}

Thermogravimetric analysis (TGA) for complexes $\mathbf{1}, \mathbf{2}$ and 3 were recorded under a nitrogen atmosphere. The TGA result for complex 1 shows an initial weight loss of $16.07 \%$ at about $200{ }^{\circ} \mathrm{C}$, corresponding to the removal of six water molecules per formula unit $(16.35 \%$ calculated). Heating above $500{ }^{\circ} \mathrm{C}$ results in complete collapse of complex 1 accompanied by a rapid mass change as the organic component burns off. The two water molecules in complex 2 are lost at about $115^{\circ} \mathrm{C}$ with mass loss of $5.39 \%(5.72 \%$, calculated). Heating above $450{ }^{\circ} \mathrm{C}$ leads complete collapse of complex 2. Complex $\mathbf{3}$ loses its one water molecule at about $118{ }^{\circ} \mathrm{C}$, leading to a $3.32 \%$ loss of the formula unit (3.53\%, calculated). The complete collapse of $\mathbf{3}$ is showed above $470{ }^{\circ} \mathrm{C}$.

\section{Conclusion}

In summary, we have successfully synthesized three copper (II) complexes by the combination of coordination bonds, hydrogen bonds and $\pi-\pi$ interactions. Importantly, this type of ligand contains functional groups capable of $\mathrm{O}-\mathrm{H} \cdots \mathrm{X}(\mathrm{X}=\mathrm{N}, \mathrm{O})$ hydrogen bonds and supporting $\pi-\pi$ interactions that sustain supramolecular architectures. Complex 1 self-assembles a 1D polymeric chain by dicarboxylate bridges and exhibits a 3D framework with 1D open channels, while complexes 2 and $\mathbf{3}$ show 2D wavelike networks constructed through two kinds of hydrogen bonding $(\mathrm{O}-\mathrm{H} \cdots \mathrm{O}, \mathrm{N}-\mathrm{H} \cdots \mathrm{O})$ interactions. We anticipate $\mathrm{SO}_{4}{ }^{2-}$ and $\mathrm{C}_{2} \mathrm{O}_{4}{ }^{2-}$ could play the same role as in the complexes $\left[\mathrm{C}_{4} \mathrm{~N}_{2} \mathrm{H}_{12}\right]\left[\mathrm{Ni}_{3} \mathrm{~F}_{2}\right.$ $\left.\left(\mathrm{SO}_{4}\right)_{3}\left(\mathrm{H}_{2} \mathrm{O}\right)_{2}\right]$ [31] and $\left\{\mathrm{Zn}(\mathrm{ox})(\mathrm{py})_{2} \mathrm{H}_{2} \mathrm{O}\right\}_{n}$ [32], in which acid radical ligands link adjacent metal ions, acting as bridges. However, in complexes $\mathbf{2}$ and $\mathbf{3}$, two kinds of acid radical ligands display a chelate coordination mode. Interestingly, in $\mathbf{1}$ the host framework encapsulates cyclic $\left(\mathrm{H}_{2} \mathrm{O}\right)_{6}$ clusters that are connected into 1D arrays along the 1D open channels. These unique water cluster arrays may be important in understanding the hydrogen-bonding motifs responsible for the anomalous character of water in living systems, as well as in the study of synthetic models, useful in theoretical and computational studies.

\section{Acknowledgements}

This work was supported by the National Natural Science Foundation of China (No. 20471048) and TRAPOYT, and Specialized Research Found for the Doctoral Program of Higher Education (No. 20050697005).

\section{Appendix A. Supplementary material}

Crystallographic data for the structural analysis have been deposited with the Cambridge Crystallographic Data Centre, CCDC No. 294,845 for 1, 294,843 for $\mathbf{2}$ and 294,844 for 3. Copies of this information may be obtained free of charge on application to CCDC, 12 Union Road, Cambridge CB2 1EZ, UK (fax: +44 1223336 033; e-mail: deposit@ccdc.cam.ac.uk or http://www.ccdc.cam.ac.uk). Supplementary data associated with this article can be found, in the online version, at doi:10.1016/j.poly. 2006.07.012.

\section{References}

[1] S.R. Batten, R. Robson, Angew. Chem., Int. Ed. 37 (1998) 1461.

[2] J.M. Lehn, Supramolecular Chemistry: Concepts and Perspectives, VHC, Weinheim, 1995.

[3] M. Munakata, L.P. Wu, T. Kuroda-Sowa, M. Maekawa, K. Moriwaki, S. Kitagawa, Inorg. Chem. 36 (1997) 5416.

[4] C. Juan, R. Mareque, B. Lee, Coord. Chem. Rev. 183 (1999) 43.

[5] S.A. Bourne, A. Mondal, M.J. Zaworotko, Cryst. Eng. 4 (2001) 25.

[6] A.S. Batsanov, M.J. Begley, P. Hubberstey, J. Stroud, J. Chem. Soc., Dalton Trans. (1996) 1947.

[7] M. Kondo, M. Shimaura, S. Noro, T. Yoshitomi, S. Minakoshi, S. Kitagawa, Chem. Lett. (1999) 285.

[8] L. Carlucci, G. Ciani, D.M. Proserpio, J. Chem. Soc., Dalton Trans. (1999) 1799.

[9] Y.J. Kang, S.S. Lee, K.M. Park, S.H. Lee, S.O. Kang, J.J. Ko, Inorg. Chem. 40 (2001) 7027

[10] H.-J. Choi, M.P. Suh, J. Am. Chem. Soc. 120 (1998) 10622.

[11] K.S. Min, M.P. Suh, J. Am. Chem. Soc. 122 (2000) 6834.

[12] A.J. Blake, N.R. Champness, P.A. Cooke, J.E.B. Nicolson, C. Wilson, J. Chem. Soc., Dalton Trans. (2000) 3811.

[13] J. Fan, M.-H. Shu, T. Okamura, Y.-Z. Li, W.-Y. Sun, W.-X. Tang, N. Ueyama, New J. Chem. 27 (2003) 1307.

[14] M.G. Barandika, M.L. Hernandez-Pino, M.K. Urtiaga, R. Cortes, L. Lezama, M.I. Arriortua, T. Rojo, J. Chem. Soc., Dalton Trans. (2000) 1469

[15] C.-J. Wang, Y.-Y. Wang, H.-R. Ma, H. Wang, Q.-Z. Shi, S.-M. Peng, Polyhedron 25 (2006) 195.

[16] U. Mukhopadhyay, I. Bernal, Cryst. Growth Des. 5 (2005) 1687.

[17] U. Mukhopadhyay, I. Bernal, Cryst. Growth Des. 6 (2006) 363.

[18] R. Custelcean, C. Afloroaei, M. Vlassa, M. Polverejan, Angew. Chem., Int. Ed. 39 (2000) 3094.

[19] R. Custelcean, C. Afloroaei, M. Vlassa, M. Polverejan, Angew. Chem., Int. Ed. 112 (2000) 3224.

[20] C. Foces-Foses, F.H. Cano, M. Martinez-Ripoll, R. Faure, C. Roussel, R.M. Claramunt, C. Lopez, D. Sanz, Elguero, J. Tetrahedron Asymmetry 1 (1990) 65.

[21] K.-M. Park, R. Kuroda, T. Iwamoto, Angew. Chem. 105 (1993) 939.

[22] K.-M. Park, R. Kuroda, T. Iwamoto, Angew. Chem., Int. Ed. Engl. 32 (1993) 884.

[23] G.M. Sheldrick, SADABs: Siemens Area Detector Absorption Correction Software, University of Göttingen, Göttingen, 1996.

[24] G.M. Sheldrick, SHELXL-97: Program for Structure Refinement, University of Göttingen, Göttingen, 1997.

[25] A.H. Narten, W.E. Thiessen, L. Blum, Science 217 (1982) 1033

[26] K.-Y. Choi, Y.- M. Jeon, H. Ryu, J.-J. Oh, H.-H. Lim, M.-W. Kim, Polyhedron 23 (2004) 903. 
[27] G. Thomas, L. Thomas, F. Roland, Eur. J. Inorg. Chem. (2004) 394.

[28] A. Volger, H. Kunkely, Coord. Chem. Rev. 177 (1998) 81.

[29] R.M. Berger, D.D. Ellis, Inorg. Chim. Acta 241 (1996) 1.

[30] S. Das, P.K. Bharadwaj, Cryst. Growth Des. 6 (2006) 187.
[31] J.N. Behera, K.V. Gopalkrishnan, C.N.R. Rao, Inorg. Chem. 43 (2004) 2636

[32] S.K. Ghosh, G. Savitha, P.K. Bharadwaj, Inorg. Chem. 43 (2004) 5495. 